\title{
Optimized Ultrasound-Assisted Oxidative Desulfurization Process of Simulated Fuels over Activated Carbon-Supported Phosphotungstic Acid
}

\author{
Peniel Jean Gildo ${ }^{1}$, Nathaniel Dugos ${ }^{1, *}$, Susan Roces $^{1}$ and Meng-Wei Wan ${ }^{2}$ \\ ${ }^{1}$ Chemical Engineering Department, De La Salle University - Manila, 2401 Taft Avenue, Malate, Manila, Philippines, 0922 \\ ${ }^{2}$ Department of Environmental Resources Management, Chia Nan University of Pharmacy and Science, 60 Erh-Jen Rd., Sec.1, Jen- \\ Te, Tainan, Taiwan, 71710
}

\begin{abstract}
Recent technological advancements respond to the call to minimize/eliminate emissions to the atmosphere. However, on the average, fuel oils which is one of the major raw materials, is found to increase in sulfur concentration due to a phenomenon called thermal maturation. As such, a deeper desulfurization process is needed to obtain low/ultra-low sulfur fuel oils. In the present study, the ultrasound assisted oxidative desulfurization (UAOD) processes using the $\mathrm{H}_{2} \mathrm{O}_{2}$ and $\mathrm{HPW}-\mathrm{AC}$ oxidizing system applied to simulated fuel ( $\sim 2800 \mathrm{ppm}$ sulfur in the form of dibenzothiophene, benzothiophene, and thiophene dissolved in toluene), were optimized. After the pre-saturation of the HPW-AC with the simulated fuel, $\mathrm{H}_{2} \mathrm{O}_{2}$ was added just before the reaction was commenced under ultrasonic irradiation. After the application of both $2^{\mathrm{k}}$-factorial design of experiment for screening and Face-Centered Design of Experiment for optimization, it was found that $25.52 \mathrm{wt} \%$ of $\mathrm{H}_{2} \mathrm{O}_{2}$ concentration, $983.9 \mathrm{mg}$ of catalyst dose, $9.52 \mathrm{~mL}$ aqueous phase per $10 \mathrm{~mL}$ of the organic phase and 76.36 minutes of ultrasonication time would render $94.74 \%$ oxidation of the sulfur compounds in the simulated fuel. After the application of the optimized parameters to kerosene and employing a 4-cycle extraction using acetonitrile, $99 \%$ of the original sulfur content were removed from the kerosene using the UAOD optimized parameters. The desulfurization process resulted in a low-sulfur kerosene which retained its basic fuel properties such as density, viscosity and calorific value.
\end{abstract}

\section{Introduction}

Sulfur oxides $\left(\mathrm{SO}_{\mathrm{x}}\right)$ and particulate matter $(\mathrm{PM})$ are one of the criteria pollutants set by the United States Environmental Protection Agency that significantly contributes to air pollution. These are particularly emitted by processes utilizing raw materials such as crude oils and metal ores - in which sulfur is prevalent. Legislative efforts have been exerted by various countries and regions to prevent the addition of these criteria pollutants to the atmosphere. Developed countries such as Japan, USA, Canada and the European Union have set a 50 ppm sulfur (low-sulfur oil, Euro IV) limit for its petroleum products while Taiwan has implemented a $10 \mathrm{ppm}$ sulfur limit (ultra-low sulfur oil, Euro V). The Philippines has recently implemented its Euro IV Standard in the mid-2016s.

Although efforts have been done to decrease the emission of sulfur pollutants, scientists and engineers have to continually develop the process they utilize to meet these standards because of thermal maturation - the natural increase in the sulfur concentration of crude oil obtained from sources [1]. Thus, the existing technologies for desulfurization needs to be intensified to be able to handle the increasing sulfur concentration of the crude oil as well as the increasingly stringent legislation against sulfur emissions.
Because of this, the currently applied industrial process of fuel desulfurization, which is hydrodesulfurization (HDS) is operated using extreme conditions - high temperatures and high pressures [2]. Also, the most common sulfur compounds in a fuel, which are dibenzothiophenes (DBT), benzothiophenes (BT), and thiophenes (T) - refractory compounds - were found to be less reactive to HDS [3]. It is for these reasons that HDS needs either an assistance or replacement and intensification.

Oxidative desulfurization (ODS) has gained interest in the recent years because of its potential to answer the concerns in HDS. For one, ODS can be accomplished using ambient conditions and without the use of the expensive hydrogen gas. The use of heteropolyacids (HPAs), particularly phosphotungstic acid, as catalysts in a hydrogen peroxide oxidizing system has proved to be effective (more than $99 \%$ efficient) in oxidizing the sulfur compounds [4]. Supporting this HPA can improve its catalytic activity by increasing the effective surface area and making it more economical because less HPW is utilized in the process and the catalyst may be recovered by simpler separation methods.

In this paper, the application of ultrasonication as assistance to ODS process - Ultrasound-Assisted Oxidative Desulfurization or UAOD - was investigated. Ultrasonic irradiation creates fine emulsions that

Corresponding author: nathaniel.dugos@dlsu.edu.ph 
improve the mass transfer between the organic and aqueous phases. In addition, UAOD promotes cavitation that creates local conditions of extreme pressures and temperature that aids the oxidation as well $[5,6]$. More specifically, the focus of the paper was the optimization of the UAOD process varying parameters such as $\mathrm{H}_{2} \mathrm{O}_{2}$ concentration, catalyst dose, AP:OP ratio and reaction time under a constant ultrasonication condition. The optimization process using a response surface methodology as well as the use concentrated simulated fuel ( 2800 ppm sulfur) has yet to be investigated.

\section{Materials and Methods}

\subsection{Chemicals and Reagents Used}

Phosphotungstic Acid $\left(\mathrm{H}_{3} \mathrm{PW}_{12} \mathrm{O}_{40}\right)$, Hydrogen peroxide $\left(\mathrm{H}_{2} \mathrm{O}_{2}, 30 \%\right.$ w/w), Dibenzothiophene $\left(\mathrm{C}_{12} \mathrm{H}_{8} \mathrm{~S}\right.$, 98-99\% purity), and Benzothiophene $\left(\mathrm{C}_{8} \mathrm{H}_{6} \mathrm{~S},>99 \%\right.$ purity) were purchased from Merck, Inc. Thiophene $\left(\mathrm{C}_{4} \mathrm{H}_{4} \mathrm{~S}, \geq 99 \%\right)$ was purchased from Sigma Aldrich while Toluene $\left(\mathrm{C}_{7} \mathrm{H}_{8}, \mathrm{AR}\right.$ grade) was purchased from RCI Labscan Ltd and Activated Carbon was purchased from Fluka Analytical.

\subsection{Equipment and Instrumentation Used}

A Vulcan ${ }^{\circledR}$ Box Furnace with Programmable Controls Model 3-550 was used to dry and calcine the catalysts. Ultrasonic irradiation was provided by an Elmasonic E $120 \mathrm{H}$ Ultrasound Cleaning Unit $(37 \mathrm{kHz}, 150 \mathrm{~W})$. Immediate separation of organic and aqueous phases of the samples was carried out using Hermele Small Centrifuge Z $206 \mathrm{~A}$ at $4000 \mathrm{rpm}$ for 20 minutes. The simulated fuel samples were analyzed using a Perkin Elmer Clarus 500 Gas Chromatograph - Flame Ionization Detector with the oven temperature initially at $100^{\circ} \mathrm{C}$, increased at a rate of $5^{\circ} \mathrm{C} / \mathrm{min}$ until $200^{\circ} \mathrm{C}$ and then at a rate of $10^{\circ} \mathrm{C} / \mathrm{min}$ until $290^{\circ} \mathrm{C}$. FID and Injection Temperature both at $300^{\circ} \mathrm{C}$ and $\mathrm{H}_{2}$ and Air were set at $45 \mathrm{~mL} / \mathrm{min}$ and $450 \mathrm{~mL} / \mathrm{min}$ respectively. The carrier gas was $\mathrm{He}$ and $\mathrm{N}_{2}$ at $1 \mathrm{~mL} / \mathrm{min}$.

\subsection{Preparation of Catalysts}

Activated carbon-supported phosphotungstic acid, thus labelled HPW-AC, was prepared following the proceeding procedures. Based on a previous experiment, the loading of HPW on AC was set to $10 \%$, thus, HPWAC-10. To synthesize HPW-AC-10, 1 gram of HPW was dissolved in excess deionized water. Ten grams of activated carbon was slowly added to the solution which was then set aside for 24 hours. The mixture was then put in a programmable furnace and dried at $120^{\circ} \mathrm{C}$ for 12 hours and calcined at $350^{\circ} \mathrm{C}$ for 4 hours. The catalysts were characterized using FTIR and SEM.

\subsection{Desulfurization of Simulated Fuel}

The simulated fuel was prepared by dissolving the three most abundant organosulfur compounds (dibenzothiophene, benzothiophene, and thiophene). About 2800 ppm of sulfur with a fixed composition of DBT, BT and T was prepared by dissolving certain amounts of these compounds in toluene. $2800 \mathrm{ppm}$ of sulfur was used to approximate the amount of sulfur in crude diesel. A volume of simulated fuel was initially obtained to be treated by oxidative desulfurization. The catalyst was pre-saturated with the solution for 5 minutes to achieve true catalytic performance [7]. Just before the reaction under sonication is commenced, a certain volume of hydrogen peroxide oxidant with a certain concentration was introduced in the solution. The reaction was commenced under ultrasound and then stopped after a certain period of time. The sample was centrifuged to easily separate the organic phase and the aqueous phase and the residual catalyst in the aqueous phase was separated by syringe filters. The organic phase was then sent to a GC-FID for analysis.

\subsection{Design of Experiment and Optimization}

To account for the factors that might have interactions in the UAOD process, a response surface methodology (RSM) design of experiment was employed - Face Centered Composite Design. Design Expert v7.0 was used to come up with the sequence of runs and analyzing the data obtained. Table 1 shows the process parameters and its corresponding range of values.

Table 1. Process Parameters and the Levels of Values used in the Design of Experiment

\begin{tabular}{|c|c|c|c|c|}
\hline \multirow{2}{*}{ Parameter } & \multicolumn{3}{|c|}{ Levels } \\
\cline { 3 - 5 } & & $-\mathbf{1}$ & $\mathbf{0}$ & $\mathbf{1}$ \\
\hline $\mathrm{A}$ & $\mathrm{H}_{2} \mathrm{O}_{2}$ Concentration (\%wt) & 10 & 20 & 30 \\
\hline $\mathrm{B}$ & Catalyst Dose (mg) & 500 & 750 & 1000 \\
\hline $\mathrm{C}$ & mL AP per 10 mL OP & 1 & 5.5 & 10 \\
\hline D & Ultrasonication Time (min) & 30 & 60 & 90 \\
\hline
\end{tabular}

A $2^{\mathrm{k}}$ factorial experiment with center points was initially done to investigate the significance of the four parameters and its interaction and if a quadratic curvature is significant $(p<0.05)$. Once confirmed, additional experimental runs were done to complete the FCC design of experiment and optimization can be performed.

\subsection{Desulfurization of Actual Fuel and Determination of Fuel Properties}

Once the optimized parameters were determined, these were applied to the actual fuel - kerosene. An additional step of actually removing the oxidized sulfur compounds was done after sufficient amount of sample has been processed. The oxidized sulfur compounds was extracted from the sample using a four-cycle extraction using acetonitrile producing the desulfurized fuel. The samples were sent to an external testing laboratory to analyze for 
the sulfur content before and after the desulfurization process. In addition to the sulfur content, fuel properties such as density and viscosity were determined. The higher heating value (HHV) of the desulfurized kerosene was estimated using an empirical formula shown [8]:

$$
\begin{gathered}
\text { API }=\frac{141.5}{\text { s.g. }}-131.5 \\
\mathrm{HHV}=42,890+93(\text { API }-10) \quad \mathrm{kJ} / \mathrm{kg}
\end{gathered}
$$

\section{Results and Discussion}

\subsection{Characterization of the Catalysts}

Figure 1 shows the SEM images of the activated carbon (a), HPW (b), and the HPW-AC-10 catalyst (c). Figure $1 \mathrm{~b}$ shows the more orderly HPW and the more chaotic Figure 1c indicates the scattering of HPW on the surface of the activated carbon which indicates the efficiency of the impregnation process and one of the reasons why HPW-AC is an efficient catalyst.

Figure 2 shows the FTIR chromatograph of the AC, HPW and HW-AC-10 catalysts. The chromatograms confirmed the presence of the HPW on the surface of AC because of the presence of $\mathrm{P}-\mathrm{O}, \mathrm{W}-\mathrm{O}, \mathrm{W}-\mathrm{O}_{\mathrm{b}}-\mathrm{W}, \mathrm{W}-$ $\mathrm{O}_{\mathrm{c}}-\mathrm{W}$ peaks which were present in the HPW chromatograms as well as in previous studies [9].

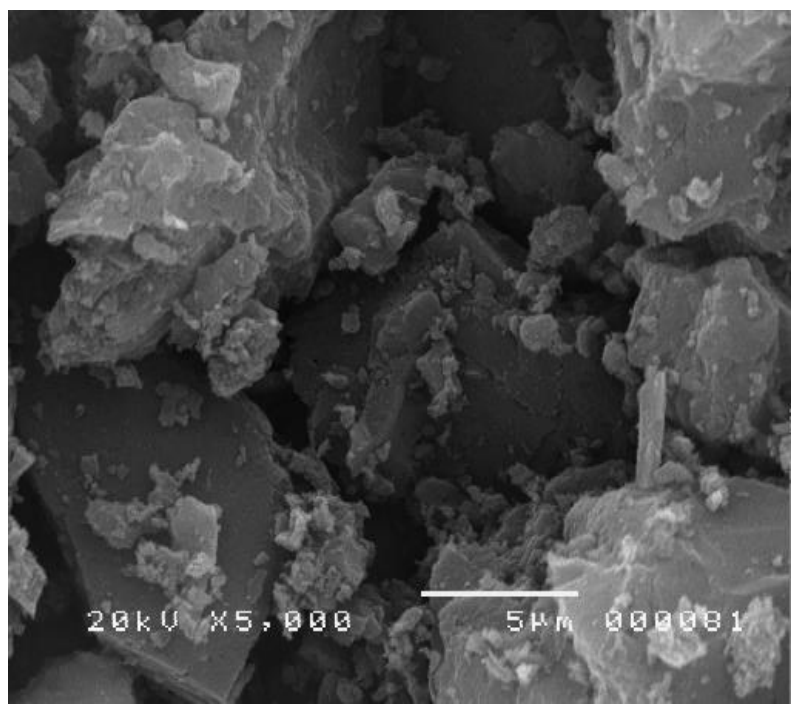

Fig. 1a. Scanning Electron Microscope Image of the Activated Carbon (AC) at 5,000x Magnification

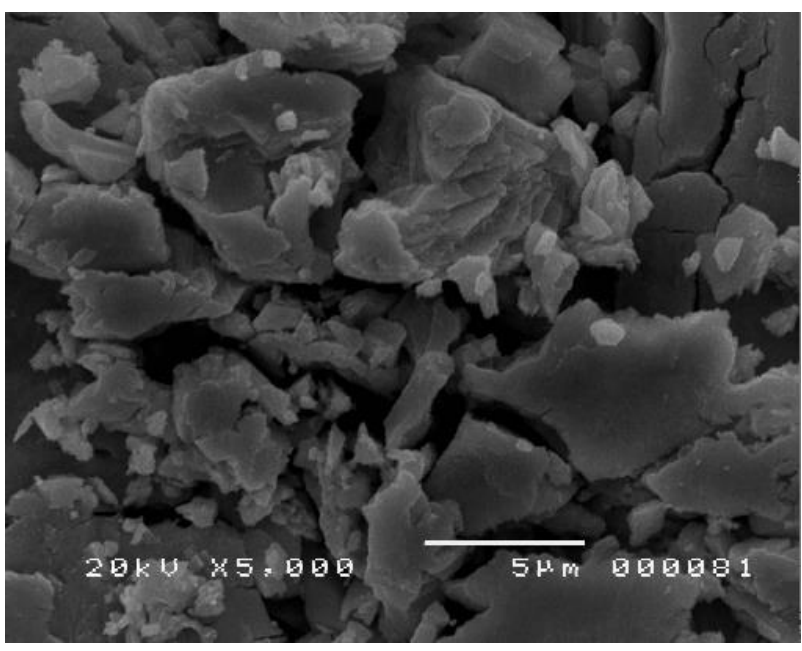

Fig. 1b. Scanning Electron Microscope Image of the Phosphotungstic Acid (HPW) at 5,000x Magnification

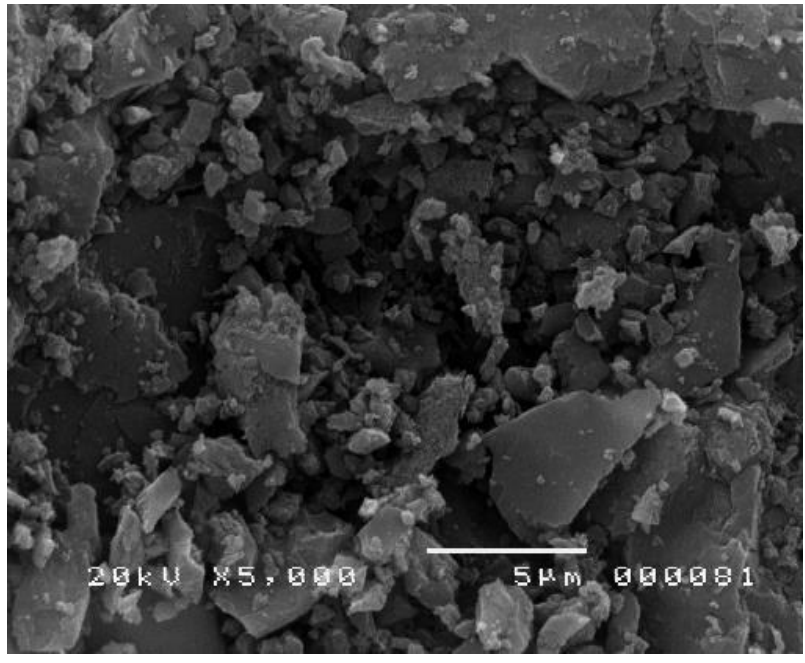

Fig. 1c. Scanning Electron Microscope Image of the Activated Carbon-Supported Phosphotungstic Acid (HPW-AC) at 5,000x Magnification

\section{2. $2^{\mathrm{k}}$ Factorial Design of Experiments}

In previous experiments, the proponents have investigated the performance of various HPW-AC loading and it has indicated that the optimal loading was $10 \%$, thus, in this paper and in further experiments, this loading is used. Increasing the loading more than $10 \%$ did not increase the percent oxidation and it may be hypothesized that HPW will not attach on the activated carbon due to overcrowding of molecules, though this has yet to be confirmed. Table 2 shows the $2^{\mathrm{k}}$ factorial experimental runs with their corresponding percent oxidations. 


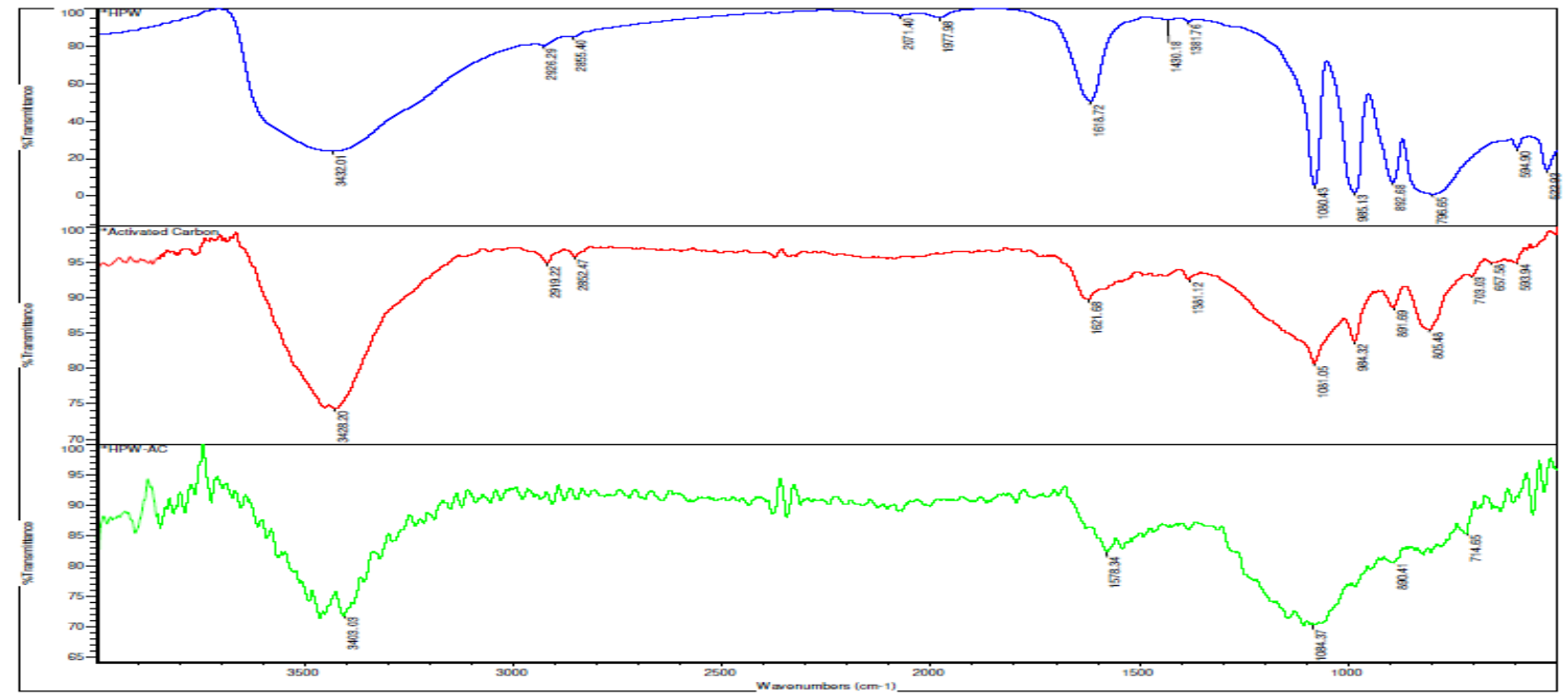

Fig. 2. FTIR Chromatograms of HPW, Activated Carbon and HPW-AC-10

Table 2. $2^{\mathrm{k}}$ Factorial Runs for UAOD applied to Simulated Fuel with their corresponding Percent Oxidations

\begin{tabular}{|c|c|c|c|c|c|}
\hline Run No. & A & B & C & D & \%Oxidation \\
\hline 1 & 10 & 500 & 1 & 90 & 70.47 \\
\hline 2 & 30 & 1000 & 1 & 30 & 78.72 \\
\hline 3 & 10 & 1000 & 1 & 90 & 67.57 \\
\hline 4 & 30 & 1000 & 10 & 90 & 96.64 \\
\hline 5 & 30 & 500 & 1 & 30 & 64.39 \\
\hline 6 & 30 & 500 & 1 & 90 & 82.37 \\
\hline 7 & 30 & 500 & 10 & 90 & 86.64 \\
\hline 8 & 20 & 750 & 5.5 & 60 & 85.47 \\
\hline 9 & 20 & 750 & 5.5 & 60 & 81.46 \\
\hline 10 & 10 & 1000 & 10 & 30 & 77.53 \\
\hline 11 & 20 & 750 & 5.5 & 60 & 84.28 \\
\hline 12 & 30 & 1000 & 1 & 90 & 88.74 \\
\hline 13 & 10 & 500 & 1 & 30 & 46.32 \\
\hline 14 & 30 & 1000 & 10 & 30 & 84.80 \\
\hline 15 & 20 & 750 & 5.5 & 60 & 82.72 \\
\hline 16 & 10 & 1000 & 1 & 30 & 59.98 \\
\hline 17 & 10 & 1000 & 10 & 90 & 86.91 \\
\hline 18 & 10 & 500 & 10 & 30 & 55.43 \\
\hline 19 & 10 & 500 & 10 & 90 & 71.75 \\
\hline 20 & 30 & 500 & 10 & 30 & 68.44 \\
\hline
\end{tabular}

It can be noted that the HPW-AC shows high efficiency in terms of oxidizing the sulfur compounds ranging from a low oxidation of $46.32 \%$ and $96.64 \%$ as the highest oxidation efficiency. The numbers show that the HPW-AC oxidation system is an efficient oxidation system that can oxidize higher sulfur concentrations of $\sim 2800$ ppm S compared to previous literatures which only utilized $\sim 500 \mathrm{ppm} S$ feedstock. This shows the potential of the HPW-AC oxidation system as a standalone ODS system rather than an assistance to HDS. It must also be noted that the system could not approach a near $100 \%$ oxidation because of the presence of thiophene, the most unreactive of all the sulfur compounds present in the fuel. This oxidation suggests that the less unreactive benzothiophene, was also oxidized by the HPW-AC oxidation system. Thus, it can noted that the organic sulfur compounds were reactive to the HPW-AC oxidation system in the following order: DBT $>$ BT $>$ T, owing to the electron densities of each sulfur compounds.

The data obtained comprises the $162^{\mathrm{k}}$ factorial runs with additional four center points; these were also processed to see the factors and their interactions were significant and to see if the curvature is significant as well. Table 3 shows the significant factors and interactions from the $2^{\mathrm{k}}$ factorial runs.

Table 3 indicates that all of the individual parameters $-\mathrm{H}_{2} \mathrm{O}_{2}$ concentration, Catalyst Dose, AP per $10 \mathrm{~mL}$ OP and ultrasonication time - were all significant while Interactions $\mathrm{AC}, \mathrm{BC}, \mathrm{BD}$, and $\mathrm{ABC}$ were shown to be significant with $\mathrm{p}$ values below 0.05 . These factors were retained in the Face Centered Design of Experiment because of their significance. Since the curvature was found to be significant also, a quadratic model is must be used for the analysis of the design space.

Table 3. Significant Parameters for UAOD applied to Simulated Fuels

\begin{tabular}{|c|c|}
\hline Source & $\mathrm{p}$-value \\
\hline Model & $<0.0001$ \\
\hline $\mathrm{A}-\mathrm{H}_{2} \mathrm{O}_{2}$ Concentration & $<0.0001$ \\
\hline B-Catalyst Dose & $<0.0001$ \\
\hline C-AP per $10 \mathrm{~mL} \mathrm{OP}$ & $<0.0001$ \\
\hline D-Ultrasonication Time & $<0.0001$ \\
\hline $\mathrm{AB}$ & 0.9001 \\
\hline $\mathrm{AC}$ & 0.0087 \\
\hline $\mathrm{BC}$ & 0.0020 \\
\hline $\mathrm{BD}$ & 0.0007 \\
\hline $\mathrm{ABC}$ & 0.0212 \\
\hline Curvature & $<0.0001$ \\
\hline \multicolumn{2}{|l|}{ Residual } \\
\hline Lack of Fit & 0.4774 \\
\hline
\end{tabular}




\subsection{Face Centered Design of Experiment}

A Face Centered Design of Experiment was employed for further analysis and optimization since this utilizes the runs used in the $2^{\mathrm{k}}$ factorial experiments. Since there will be no change in the parameters to be considered (because they were deemed significant), this design can be employed by just adding some additional experimental points. Table 4 shows these additional points and their percentage oxidations. Table 5 shows the significant parameters of the RSM FCC Design of Experiment.

The quadratic model utilized in the ANOVA table can now be appropriately explored. The ANOVA shows that all the model and its individual factors were all significant. $\mathrm{AC}, \mathrm{BC}$, and $\mathrm{BD}$ interactions were also significant. The square of the terms $\mathrm{A}, \mathrm{C}$ and $\mathrm{D}$ were also found to be significant. It should also be noted that the Lack of Fit was found to be not significant at a value of 0.5251 . The value of the $\mathrm{R}^{2}$, which is 0.9761 , indicates that the quadratic model was more appropriate for use than the two-factor interaction model which was done in the previous section.

Table 4. Additional Experimental Points for RSM Face Centered Design of Experiment for UAOD applied to Simulated Fuel with their corresponding Percent Oxidations

\begin{tabular}{|c|c|c|c|c|c|}
\hline Run No. & A & B & C & D & \%Oxidation \\
\hline 21 & 20 & 1000 & 5.5 & 60 & 91.84 \\
\hline 22 & 20 & 500 & 5.5 & 60 & 75.69 \\
\hline 23 & 20 & 750 & 5.5 & 60 & 84.28 \\
\hline 24 & 20 & 750 & 10 & 60 & 85.20 \\
\hline 25 & 10 & 750 & 5.5 & 60 & 75.41 \\
\hline 26 & 30 & 750 & 5.5 & 60 & 90.15 \\
\hline 27 & 20 & 750 & 5.5 & 90 & 89.28 \\
\hline 28 & 20 & 750 & 5.5 & 30 & 74.14 \\
\hline 29 & 20 & 750 & 5.5 & 60 & 86.33 \\
\hline 30 & 20 & 750 & 1 & 60 & 78.96 \\
\hline
\end{tabular}

Table 5. Significant Parameters of the UAOD Applied to Simulate Fuels

\begin{tabular}{|l|c|}
\hline \multicolumn{1}{|c|}{ Source } & p-value \\
\hline Model & $<0.0001$ \\
\hline $\mathrm{A}-\mathrm{H}_{2} \mathrm{O}_{2}$ Concentration & $<0.0001$ \\
\hline $\mathrm{B}-$ Catalyst Dose & $<0.0001$ \\
\hline $\mathrm{C}-\mathrm{AP}$ per 10 mL OP & $<0.0001$ \\
\hline $\mathrm{D}-$-Ultrasonication Time & $<0.0001$ \\
\hline $\mathrm{AC}$ & 0.0103 \\
\hline $\mathrm{BC}$ & 0.0016 \\
\hline $\mathrm{BD}$ & 0.0004 \\
\hline $\mathrm{A}^{2}$ & 0.0371 \\
\hline $\mathrm{C}^{2}$ & 0.0120 \\
\hline $\mathrm{D}^{2}$ & 0.0064 \\
\hline Residual & \\
\hline \multicolumn{2}{|c|}{ Lack of Fit } \\
\hline
\end{tabular}

The insignificant lack of fit supports the adequacy of the model generated since it indicates that the model can predict and approximate the dependent variable (percent oxidation) with great accuracy should one try to repeat the experiments using various combinations of the independent variables. The model that the software generated is shown in Equation 3 with all the terms used in the equation being the actual values of the parameters.

$\%$ Oxidation $=$

$$
\begin{aligned}
& -11.43105+2.07760 A+0.03380 B \\
& +2.25346 C+1.00967 D-0.03469 A C \\
& +0.00179 B C-0.00032 B D-0.02918 A^{2} \\
& -0.17852 C^{2}-0.00443 D^{2}
\end{aligned}
$$

\subsection{Model Graphs}

Figure 3 shows the model graphs of the significant factors and interactions indicated by the ANOVA. Should an individual factor be deemed significant in any of the interactions, single factor variations were not shown.

Fig. 3a shows the interaction plot of the $\mathrm{H}_{2} \mathrm{O}_{2}$ concentration (A) with the AP per $10 \mathrm{~mL}$ OP (C). At high levels of $A$ and $C$, high oxidation was shown. This increase in oxidation with an increase of $\mathrm{A}$ and $\mathrm{C}$ can be attributed to the amount of $\mathrm{H}_{2} \mathrm{O}_{2}$ species which serve two functions: (1) direct oxidation of the sulfur compounds by the increased hydroxyl radicals from the $\mathrm{H}_{2} \mathrm{O}_{2}$ enhanced further by ultrasonic irradiation and (2) its interaction with the catalyst to form a peroxo-metallate complex which are more reactive to organic sulfur compounds. The increase in AP could entail the same effect (increase in $\mathrm{H}_{2} \mathrm{O}_{2}$ ) but to a certain extent only. This might be because of the scattering of the catalyst on the two phases. In the experiments, it was seen that the catalyst had an affinity to both the OP and AP thus increase AP so much would make less contact with the

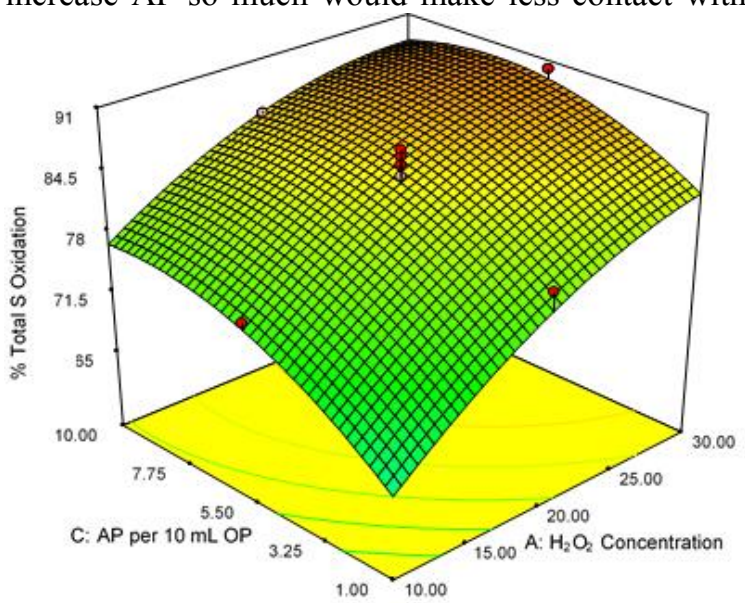

Figure 3a 

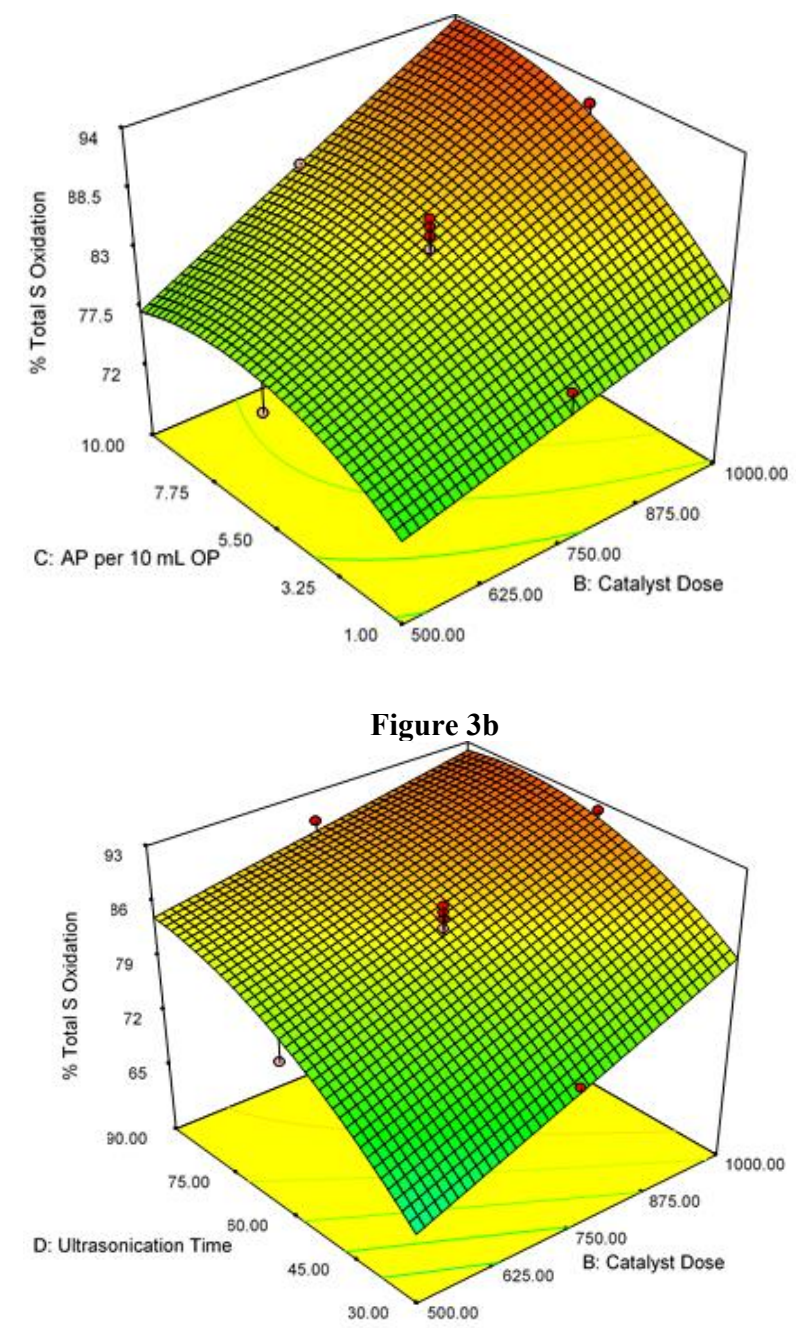

Figure 3c

Fig. 3. Model Graphs of Variables for UAOD Applied to Simulated Fuel: (a) $\mathrm{H}_{2} \mathrm{O}_{2}$ Concentration and AP per $10 \mathrm{~mL}$ OP Interaction Plot; (b) Catalyst Dose and AP per $10 \mathrm{~mL}$ OP Interaction Plot; (c) Catalyst Dose and Ultrasonication Time Interaction Plot

OP. As the reaction proceeds with ultrasonication, the catalyst was seen to scatter on both phases. This causes more losses of the catalyst on the AP rather than facilitating the reaction in the OP. Using a sufficient amount of AP to just the right level would provide $\mathrm{H}_{2} \mathrm{O}_{2}$ for the oxidation as well as sufficient contact with the OP.

Figure $3 b$ shows a steep surface that increases in percent oxidation with the increase of both the catalyst dose and AP per $10 \mathrm{~mL}$ OP. As expected, an increase in the percent oxidation was shown with the increase of catalyst dose because of the increase in the active species that would produce the peroxo-metallate complex. At smaller catalyst doses, however, a sufficient amount of AP should be provided at a moderate level only due to the affinity of the activated carbon catalyst to both phases. At this lower level, the system does not have enough catalyst to form the complex and substantially oxidize the sulfur compounds. In addition, the increase in the solid materials in the system increases the nucleation sites for the formation of cavities to occur. These cavities are known to form local conditions of extreme temperatures and pressure thus, increasing the production of chemically active species such as the radicals and complexes [10].

Figure $3 \mathrm{c}$ shows the interaction plot of catalyst dose (B) and ultrasonication time (D). Both of these parameters have a positive effect on the oxidation. Ultrasonication and the solid catalyst have a synergistic effect on the oxidation reaction because of the presence of the solid particles. The solid particles provide additional nucleation sites for the cavity formation to occur thus, there is an increase in cavitational intensity and consequently, better sonochemical effects [10]. The intensified cavitation increases the hydroxyl radical production thereby increasing the oxidation of the sulfur compounds. At low levels of catalyst dose, an increase in the ultrasonication time not only forms more radicals but also increases the interfacial mass transfer and provides more contact time for the sulfur compounds and oxidant responsible for its conversion be it the hydroxyl radicals or the peroxo-metallate complex.

\subsection{Optimized UAOD Parameters}

Based on the model generated, optimized parameters for the ultrasound-assisted oxidative desulfurization applied to simulated fuel were found to be $25.52 \mathrm{wt} \% \mathrm{H}_{2} \mathrm{O}_{2}$ concentration, $983.9 \mathrm{mg}$ of catalyst dose, $9.52 \mathrm{~mL}$ per 10 $\mathrm{mL} \mathrm{OP}$ and 76.36 minutes of ultrasonication time. Table 6 summarizes these optimized values. The table also shows the predicted percent oxidation of the system based on the model at these conditions which is $97.02 \%$. Confirmatory runs were also done to check the validity of the model and an adequate $2.35 \%$ error was obtained with the actual oxidation efficiency of $94.74 \%$.

Table 6. Optimized UAOD Parameters applied to Simulated Fuel

\begin{tabular}{|c|c|}
\hline Parameter & Value \\
\hline $\mathrm{H}_{2} \mathrm{O}_{2}$ Concentration & $25.52 \mathrm{wt} \%$ \\
\hline Catalyst Dose & $983.9 \mathrm{mg}$ \\
\hline AP per 10 mL OP & $9.52 \mathrm{~mL}$ \\
\hline Ultrasonication Time & 76.36 minutes \\
\hline \%Oxidation (Predicted) & $97.02 \%$ \\
\hline \%Oxidation (Actual) & $94.74 \%$ \\
\hline Error & $2.35 \%$ \\
\hline
\end{tabular}

\subsection{Application to Actual Liquid Fuel}

The optimized parameters were then applied to an actual fuel, in this study, it was kerosene. After that, removal of the oxidized sulfur compounds was done a four-cycle extraction procedure using acetonitrile. The sulfur content of the kerosene before the treatment was analyzed as $1370 \mathrm{ppm}$ of $\mathrm{S}$ and after the desulfurization process, the sulfur content was reduced to $14 \mathrm{ppm} \mathrm{S}-\mathrm{a}$ value that is lower than the Euro IV standard of fuels (50 ppm S) - rendering $99.0 \%$ sulfur removal. 


\subsection{Evaluation of the Fuel Properties}

The fuel properties (i.e. density, viscosity) were determined using common experimental procedures and the calorific value of the fuel was approximated using Equation 1 and 2. The density of the original kerosene was $0.7801 \mathrm{~g} / \mathrm{cm}^{3}$ while the desulfurized kerosene was found to be $0.7648 \mathrm{~g} / \mathrm{cm}^{3}$. The density of the feed kerosene was well within the typical ranges of density for kerosene -0.7750 to $0.840 \mathrm{~g} / \mathrm{cm}^{3}$. Though the density of the desulfurized kerosene was well below this range of values, this is of limited significance as fuel quality indication unless correlated to other fuel properties. Although, one may say that the less dense the fuel would make the amount of fuel per unit volume less also.

The density may be correlated to the heating value of the fuel with adequate accuracy. Once the specific gravity of the fuels were determined, the degree API can be calculated immediately followed by the calculation of the heating value. The original heating value was 46.60 $\mathrm{MJ} / \mathrm{kg}$ while the desulfurized kerosene was found to have $46.94 \mathrm{MJ} / \mathrm{kg}$ of heating value. With the decrease in density of the fuel, the estimated heating value increased, though an actual determination of heating value must be done for verification. This is because on the weight basis, the carbon (low-heating value) to hydrogen (highheating value) ratio increases as specific gravity increases [11].

The viscosity was also determined before and after the desulfurization and was found to be $0.8575 \mathrm{cP}$ and $0.8655 \mathrm{cP}$. Translating these to kinematic viscosity, in $\mathrm{cSt}$, these values are $1.09902 \mathrm{cSt}$ and $1.1317 \mathrm{cSt}$, respectively. All these values fall within the typical range of kinematic viscosity of kerosene which is 1.0 and $1.9 \mathrm{cSt}$ [11]. The increase in viscosity shows that after desulfurization, the fuels may be harder to transport using a pump.

From these, it can be said that the desulfurization of the fuel not only reduces the sulfur content of the fuel but also retains the basic properties of the fuel.

\section{Conclusions and Future Works}

The study shows the effectivity of an HPW-AC oxidation system in oxidizing sulfur compounds to sulfoxides and sulfones high efficiency. Once applied to an actual fuel, it shows that $99.0 \%$ of sulfur removal was shown resulting to a low-sulfur fuel (below $50 \mathrm{ppm}$ Euro IV standard). Using a response surface methodology of Face Centered Composite Design of Experiment, the optimal UAOD parameters were found to be $25.52 \mathrm{wt} \%$ of $\mathrm{H}_{2} \mathrm{O}_{2}, 983.9 \mathrm{mg}$ of catalyst dose, $9.52 \mathrm{~mL}$ of AP per $10 \mathrm{~mL}$ of $\mathrm{OP}$ and 76.6 minutes of ultrasonication producing $94.74 \%$ oxidation of the $2800 \mathrm{ppm}$ sulfur, a feedstock that contains relatively high concentrations of sulfur compared to typical researches indicating the possibility of applying the ODS in replacing the HDS which were indicated to be less reactive to refractory sulfur compounds or in which process intensification is needed (i.e. higher temperature and pressure). Using kerosene as an actual fuel, the sulfur content was reduced from $1370 \mathrm{ppm} \mathrm{S}$ to $14 \mathrm{ppm} \mathrm{S}$, equivalent to $99.0 \%$ desulfurization of kerosene.

The ultrasonication device used in the experiment is unable to vary certain ultrasonication parameters such as ultrasonication power and frequency. It may be suggested that further studies investigate on the effect of these parameters to the oxidation efficiency. Previous studies have indicated an $\mathrm{HPW}-\mathrm{H}_{2} \mathrm{O}_{2}$ oxidizing system was shown to follow a first-order kinetics, so in an HPW-AC oxidizing system, kinetics may also be investigated. Finally, a pilot scale design and fabrication of a continuous desulfurization process may be done.

\section{References}

1. L. Liu, H. Lü, J. Qian, J. Xing, China. Pet. Process. Pe. 12,4, 1-6 (2010).

2. X. Ma, A. Zhou, C. Song, C. Catal. Today, 123, 276-284(2007)

3. T.O. Sachdeva, K. K. Pant, Fuel Process. Technol. 91, 1133-1138 (2010)

4. H. Mei, B. W. Mei, T.F. Yen, Fuel 82, 405-414 (2003)

5. M.W. Wan, T.F. Yen, Appl. Catal. A-Gen. 319, 237-245 (2007)

6. Y. Dai, D. Zhao, Y. Qi, Ultrason. Chem. 18, 264 268 (2011).

7. L. Liu, Y. Zhang, W. Tan, W. Ultrason. Sonochem. 21, 970-974 (2014).

8. Eugene L. Keating, Applied Combustion, $2^{\text {nd }}$ ed. (Taylor and Francis Group, Florida, 2007)

9. M. Prathap Kumar, A. Sivasamy, A. International Conference on Advances in New materials (ICAN 2014) 2(1), 228-233 (2014)

10. A.G. Chakinala, P.R. Gogate, A. E. Burgess, D. H. Bremner, Ultrason. Chem. 14, 5, 509-514 (2007)

11. Salvatore J. Rand, Significance of Tests for Petroleum Products (ASTM International, 2003) 